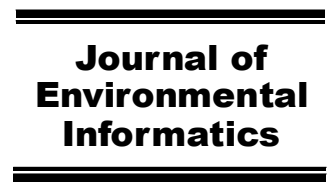

www.iseis.org/jei

\title{
Estimating Impervious Surfaces Area of Urban Watersheds Using ASTER Data
}

\author{
J. S. Yang ${ }^{1, *}$ and F. J. Artigas ${ }^{2}$ \\ ${ }^{1}$ Department of Geography, Ball State University, Muncie, IN 47306, USA \\ ${ }^{2}$ Meadowlands Environmental Research Institute, Lyndhurst, NJ 07071, USA
}

Received 24 September 2007; revised 29 May 2008; accepted 24 June 2008; published online 2 September 2008

\begin{abstract}
In this paper we present and compare two approaches in estimating impervious surfaces area for an urban watershed in northern New Jersey, United States using Advanced Spaceborne Thermal Emission and Reflection Radiometer (ASTER) imagery. The first approach is to use the spectral mixture analysis (SMA) to separate image pixels into a linear combination of three typical urban land covers: vegetation, impervious surface and soil. The other is to use the normalized difference vegetation index (NDVI) to estimate imperviousness from the same imagery. The accuracies of the estimated imperviousness were assessed using a high-resolution color-infrared orthophoto. In total, 100 polygons with areas between 3 and 6 hectares were randomly selected from five distinct land use/cover categories and the percentage of impervious surface of each polygon was digitized and calculated. The results showed that nearly 90 percent of the variation in actual impervious surfaces in this watershed can be explained by the estimated impervious surfaces by a linear regression model $\left(\mathrm{R}^{2}=0.898\right)$. The NDVI approach is recommended for urban environments with small proportion of barren soils for its simplicity, while the SMA is suitable for urban environments with approximately equally-distributed vegetation, impervious surfaces and barren soil.
\end{abstract}

Keywords: ASTER, impervious surfaces, NDVI, urban watershed

\section{Introduction}

Impervious surfaces area has been recognized as a key environmental indicator for sustainable urban development and natural resources planning (Arnold and Gibbons, 1996). Impervious surfaces are defined as impermeable anthropogenic surface materials such as asphalt, concrete and building roofs that cover a given surface area and prevent infiltration of water into the soil. Impervious surfaces allow many pollutants types, from a variety of sources, to accumulate and be washed into water bodies by storm water runoff, severely degrading the water quality (Harrison et al., 2001). Increasing imperviousness due to urban growth in an urban watershed can lead to reduced stream habitat and loss of biodiversity (Dougherty et al., 2004). Quantification of impervious surfaces in urban environments is becoming increasingly important with growing concerns over future water quality trends in the United States (Forster, 1985; Civco et al., 2002; Wu, 2004; Xian and Crane, 2005). Because impervious surfaces have higher thermal conductivities, they are also responsible for the phenomena of urban heat islands where air temperature over impervious surfaces is significantly higher compared to vegetated areas (Yuan and Bauer, 2007).

\footnotetext{
${ }^{*}$ Corresponding author. Tel.: +1765 2851761; fax: +1 7652852351 .

E-mail address: jyang@bsu.edu (J. S. Yang).
}

ISSN: 1726-2135 print/1684-8799 online

C) 2008 ISEIS All rights reserved. doi:10.3808/jei.200800118
In practice, estimating impervious surfaces area using field survey methods on a parcel basis is a time consuming and labor intensive effort. Remote sensing offers many helpful approaches for assessing and monitoring urban environments due to its rapid and repetitive monitoring capability (Slonecker et al., 2001; Yang et al., 2003; Xian and Crane, 2005). These approaches produce a raster imperviousness map that represents local probability of impervious surfaces density ranging from high to low (Mesev, 1998). A widely used method in remote sensing for parameterizing the distribution of impervious surfaces and vegetation in an urban landscape is the spectral mixture analysis (SMA) based on a vegetation-impervious surfacesoil (V-I-S) model. The V-I-S model, first proposed by Ridd (1995), states that any urban environment can be conceptualized in terms of three primary components: vegetation (V), impervious surfaces (I), and soil (S), in addition to water. It assumes that the land cover in an urban environment is a linear combination of these three components, which provides a guideline for decomposing the urban landscape and a link for those components to remote sensing spectral characteristics. This conceptual model was originally established and tested in a study in Salt Lake City, Utah and has been widely applied to parameterize biophysical composition of land cover, i.e., to quantify the distribution of green vegetation, impervious surfaces and soil of land surface when mixed pixels are concerned in using moderate-resolution remote sensing. For example, Ji and Jensen (1999) estimated the impervious surface fraction for an urban and suburban portion of Charleston, South Carolina based on sub-pixel analysis and layered classification; 
Ward et al. (2000) developed a classification approach for mapping vegetation and soil cover with moderate accuracy in Queensland, Australia; Small (2001) estimated urban vegetation distribution using a three-endmember linear mixture model; Phinn et al. (2002) estimated impervious surfaces in an urban environment in Australia using a constrained spectral mixture analysis method; Wu and Murray (2003) estimated the distribution of impervious surfaces, vegetation and soil in Ohio using spectral mixture analysis; and Wang and Zhang (2004) estimated the proportion of impervious surfaces using a SPLIT model in the Chicago metropolitan region. All of these studies were based on $30 \mathrm{~m}$ spatial resolution Landsat Thematic Mapper (TM) and /or Enhanced Thematic Mapper Plus (ETM+) data using 6 or 8 multispectral channels.

Recently, high-resolution IKONOS data (1 m for panchromatic band and $4 \mathrm{~m}$ for multispectral bands) was also used to estimate impervious surfaces (Cablk and Minor, 2003; Sawaya et al., 2003). They found that the normalized difference vegetation index (NDVI) derived from IKONOS data provides the best estimate of impervious surfaces. However, limited efforts have been made to map impervious surfaces using relatively inexpensive Advanced Spaceborne Thermal Emission and Reflection Radiometer (ASTER) imagery (Zhu and Blumbergerg, 2002). Therefore, the objective of this study is to estimate the impervious surfaces area of an urban watershed using ASTER data by different approaches.

\section{Study Area and Data}

New Jersey Watershed Management Area 5 (WMA-5) in northeastern New Jersey is an urban watershed located to the west of New York City with 42,700 hectares in size (Figure 1). Approximately 30 percent of this site is residential area, 20 percent is commercial and industrial areas and the remaining 50 percent is undeveloped. Much of the lower Hackensack River Watershed is tidal marsh known as the Hackensack Meadowlands, which is the home to more than 260 bird species including several rare and threatened New Jersey species. We chose this watershed as the study site because it is a typical urban watershed with many impervious surfaces, which have large environmental impact on the surrounding areas, especially on water quality.

ASTER is one of the NASA Terra instruments in a sun synchronous orbit $705 \mathrm{~km}$ from the Earth's surface and acquires images in a $60 \times 60 \mathrm{~km}$ "granule" (Abrams, 2000). The spatial resolution of ASTER data varies with wavelengths: 15 $\times 15 \mathrm{~m}$ for bands 1 to 3 in the visible and near-infrared (VNIR), $30 \times 30 \mathrm{~m}$ for bands 4 to 9 in the short wave infrared (SWIR) and $90 \times 90 \mathrm{~m}$ for bands 10 to 14 in the thermal infrared (TIR) region. In this study, one scene ASTER image acquired on October 20, 2003 was used to estimate the impervious surfaces area in pixel-based approaches. Sub-meter land use/cover data from the New Jersey Department of Environmental Protection (NJDEP) was used to select polygons in each land use/cover category to support the signature derivation and accuracy assessment. New Jersey statewide high-resolution color-infrared orthophoto acquired in 2002 were used to delineate and calculate the percentage of impervious surfaces of each sampled polygon in ArcGIS.

Since ASTER data have different spatial resolutions in different spectral bands, a resolution merge (fuse) was conducted to re-sample bands 4 through 9 to a resolution of 15 meters, then band 1 through band 9 were layer stacked to a new 9-band image, which was used for further analysis. In geometric correction, 27 ground control points (GCPs) were collected on both ASTER image and orthophoto and 17 of them were used to register the ASTER image to the New Jersey State Plane coordinate system (NAD 83) with a root mean square error (RMSE) of less than one. All image processing was conducted using the ENVI 4.0 software package (RSI, 2004).

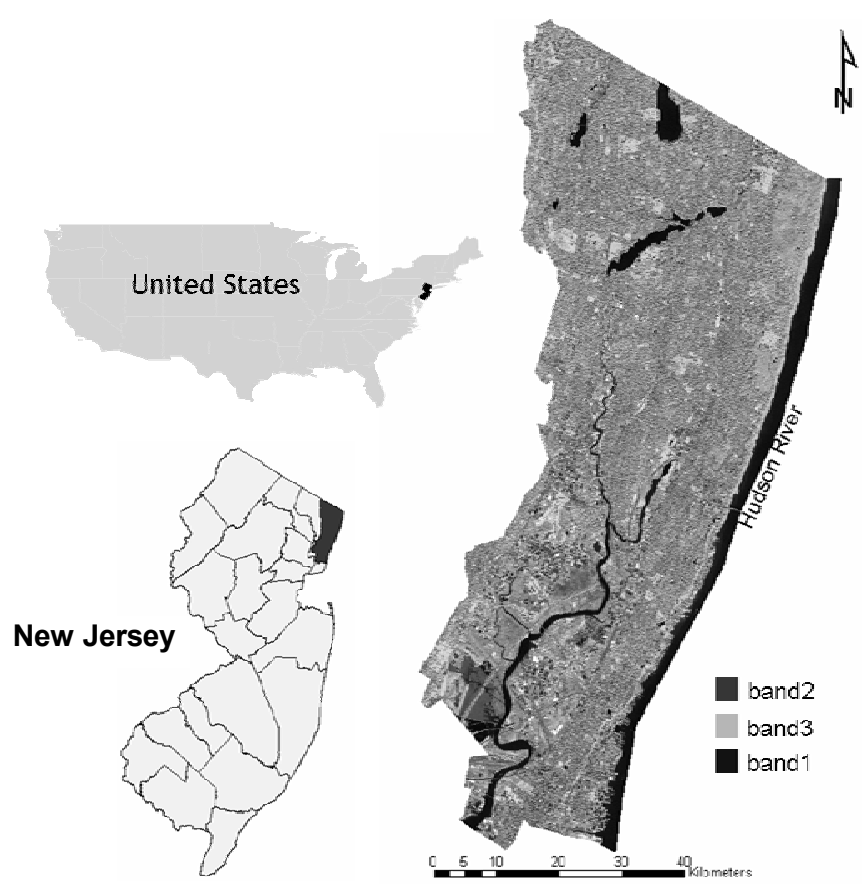

Figure 1. ASTER image with band combination of RGB = 231 for the New Jersey Watershed Management Area 5.

\section{Approaches}

For moderate-resolution remote sensing data such as Landsat TM and ETM+, the SMA is widely used to map impervious surfaces (Small, 2001; Phinn et al., 2002; Wu and Murray, 2003; Lu and Weng, 2004). For high-resolution remote sensing data like IKONON and Quickbird, the NDVI approach has better results (Cablk and Minor, 2003; Sawaya et al., 2003). In this study, both these two approaches are used to estimate the impervious surfaces area of an urban watershed using ASTER data.

\subsection{The SMA Approach}

The SMA is a method to calculate land cover fraction within a pixel and involves modeling a mixed spectrum as a combination of spectra for pure land cover types, called endmem- 
bers (Roberts et al., 1998). The SMA can be sub-classified into linear spectral mixture analysis (van der Meer and de Jong, 2000; Sabol et al., 2002) and non-linear spectral mixture analysis (Zhang et al., 1998; Gilabert et al., 2000) according to the complexity of scattering.

The linear spectral mixture model describes the land surface composition in each pixel of an image using two to six endmembers. Each endmember represents a pure land cover type. The general form of a linear SMA model is:

$R=f_{n 1} R_{1}+f_{n 2} R_{2}+\ldots+f_{n m} R_{m}+e$

where $m$ is the number of endmembers, $n$ is the number of spectral bands, $R_{i}=\left\{R_{1}, R_{2}, \ldots, R_{m}\right\}$ is the reflectance of each endmember for the $n$th band in the image, $f=\left\{f_{n 1}, f_{n 2}, \ldots, f_{n m}\right\}$ is the fraction of each endmember in a pixel, and $e$ is the unmodeled residual. The solution to the linear mixture model is based upon two assumptions: 1) the summation of $f_{i}$ must be equal to 1 , i.e., $\sum^{m} f_{i}=1$; and 2 ) the values of $f_{i}$ will always lie between 0 and $l_{i=1}^{i}$ if all spectrally unique endmembers are considered.

In this study, we assume that multiple scattering is negligible and only consider linear spectral mixtures of a V-I-S model. The V-I-S model for urban regions provides biophysical composition by assigning values obtained from satellite images for three components, namely vegetation, impervious surfaces and soil (Figure 2). In this model, the typical residential sequence of an urbanized area is shown along the V-I axis, and traditional commercial and industrial areas are situated along the I-S axis. The S-V axis represents lands that have not been urbanized, or urban lands that are undergoing changes. Bare soil may represent recent landfills or cleared land for urbanization at the edges or inside of a city.

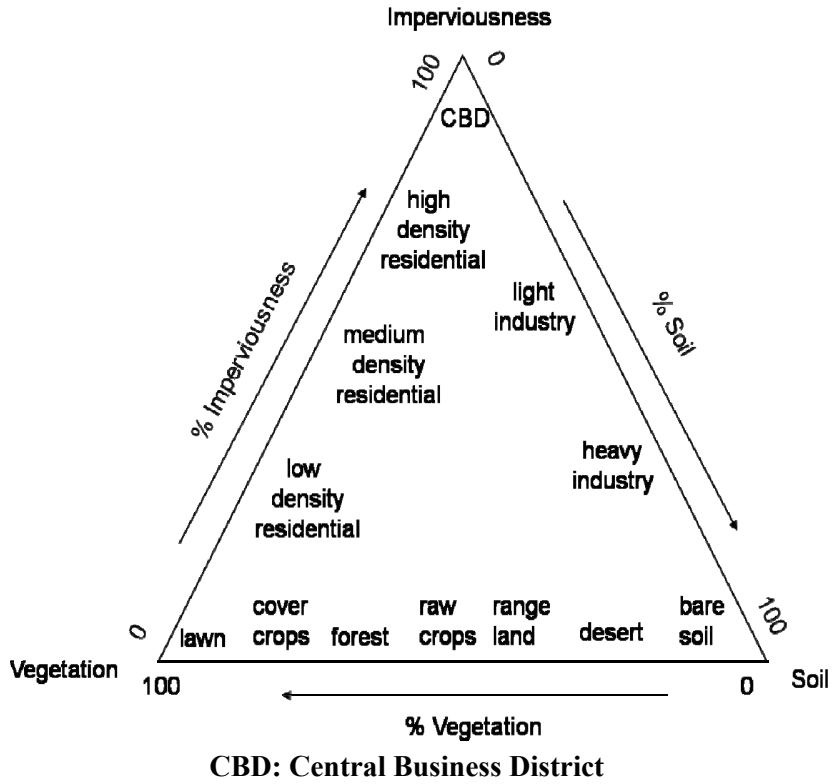

Figure 2. Vegetation-Impervious surface-Soil (V-I-S) composition model (after Ridd, 1995).
Because some land surfaces with low or high reflectance (e.g. open waters and wetlands $v s$. clouds and sands) adversely affect impervious surfaces estimation (Small, 2001), these surfaces were identified and masked before applying the V-I-S model in this study. Open waters were masked using 2002 land use/cover data for the reason that they have similar reflectance as dark roofs, making the separation from roof tops difficult using unsupervised classification alone. Similarly, wetlands were masked because they are regularly inundated by the tide and in some cases, depending on the tidal level, have similar reflectance with dark roofs. There is no sand category in this area, and the image was acquired on a clear day, therefore, the effects of sands and clouds were ignored here. After mask, only urban and suburban areas were retained for determination of percentage of impervious surfaces.

Endmembers of each V-I-S model components were selected as follows: forest and grass were selected as endmembers for vegetation, pavement (asphalt and concrete) and building roofs (dark, medium, and bright) for impervious surfaces, and landfill and barren land for soil (Table 1). The spectra of each endmember were obtained directly from the ASTER image based on existing land use/cover maps and field inspection. Finally, the SMA was applied to estimate the percentage of impervious surfaces in each pixel of the retained image.

Table 1. Land Cover Types Used to Select Endmembers in the V-I-S Model

\begin{tabular}{ccc}
\hline VIS Components & Land Cover Types & Imperviousness (\%) \\
\hline Vegetation (V) & Grasses & 0 \\
& Forest/Trees & 0 \\
Impervious & Concrete & 100 \\
Surfaces (I) & Asphalt & 100 \\
& Bright roofs & 100 \\
& Medium roofs & 100 \\
& Dark roofs & 100 \\
Soil (S) & Barren & $30-50$ \\
\hline
\end{tabular}

\subsection{The NDVI Approach}

The NDVI is derived from the reflectance values that are calculated separately in two wavebands of the spectrum according to the following equation (Carlson and Ripley, 1997):

$N D V I=\frac{\left(\alpha_{n i r}-\alpha_{v i s}\right)}{\left(\alpha_{n i r}+\alpha_{v i s}\right)}$

where $\alpha_{v i s}$ and $\alpha_{\text {nir }}$ represent surface reflectance averaged over the visible and near infrared regions of the spectrum, respectively. In this study, band $2(0.63 \sim 0.69 \mu \mathrm{m})$ and band $3(0.78$ $\sim 0.86 \mu \mathrm{m}$ ) were selected as $\alpha_{v i s}$ and $\alpha_{\text {nir }}$ to calculate NDVI values using equation (2).

Calculated NDVI values usually range from -1 to +1 , which were then normalized to a scaled NDVI $\left(\mathrm{N}^{*}\right)$ ranging from 0 to +1 using the following equation: 


$$
N^{*}=\frac{N D V I-N D V I_{s}}{N D V I_{v}-N D V I_{s}}
$$

where $N D V I_{s}$ represents values on barren soil with minimum vegetation and $N D V I_{v}$ represents values on dense forest or grass with maximum vegetation. The minimum and maximum values from the estimated NDVI image were used as $N D V I_{s}$ and $N D V I_{v}$ for this purpose.

Gillies et al. (1997) found a consistent relationship between fractional vegetation cover $\left(F_{r}\right)$ and scaled NDVI for both coarser and finer spatial resolution images as follows:

$F_{r}=N^{*^{2}}$

Ridd (1995) showed that the fraction of impervious surfaces (IS) and the fractional vegetation cover $\left(F_{r}\right)$ vary inversely in an urban environment:

$I S=\left(1-F_{r}\right)$

For easy interpretation, the final fraction of impervious surfaces was transformed to percentage by multiplying 100 .

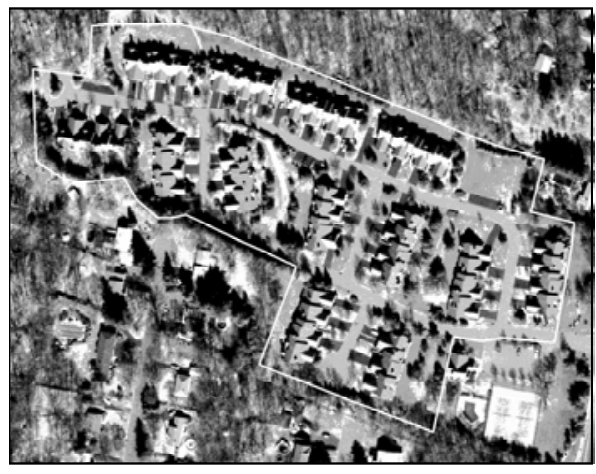

$1 \mathrm{ft}$ pixel Orthophoto

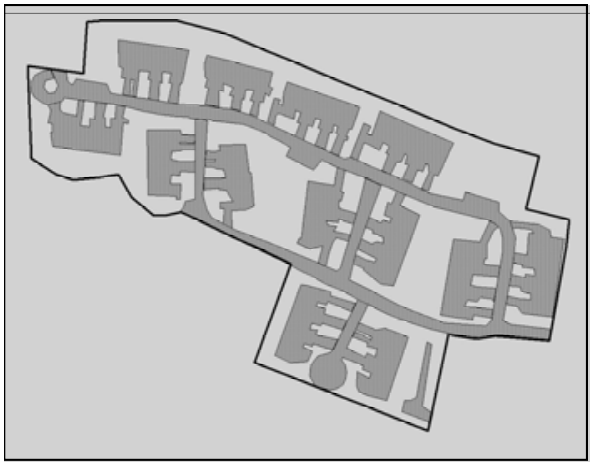

ISA from Orthophoto: $48 \%$

\subsection{Accuracy Assessment}

In accuracy assessment, two important factors needed to consider in obtaining unbiased ground reference information are sampling strategy and sample size. In this study, a stratified random sampling strategy was used to select samples from the NJDEP 2002 land use/cover data, which ensures that a minimum number of samples were selected to represent varying degrees of imperviousness in this area. The same number of samples was selected from each of the land use/cover categories, including industrial, commercial, high-density, mediumdensity and low-density residential. It is often difficult to determine the actual number of samples to be referenced on the ground and used to assess the accuracy of each individual category. However, there is a consensus among researchers that a minimum of 50 samples for each category is reasonable, both statistically and in practical terms (Jensen, 2005). Considering the compromise between statistical rigor and practical limitations, we selected 100 polygons randomly: 20 polygons for each of the five urban land categories. The sizes of sampled polygons are between 3 and 6 hectares with an average of 5 hectares, which include approximately 200 ASTER $15 \times$ $15 \mathrm{~m}$ pixels to avoid the effects of geometric registration error. For each sampled polygon, a high-resolution color-infrared or-

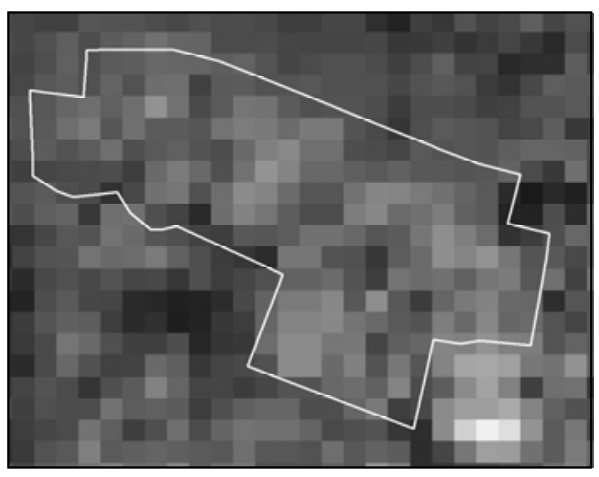

$15 \mathrm{~m}$ pixel ASTER

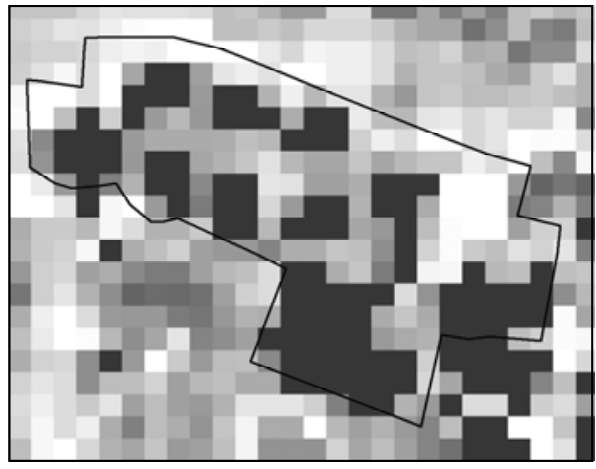

ISA from ASTER: $41 \%$

Figure 3. Impervious surfaces delineated from a high-resolution color-infrared orthophoto and estimated from the ASTER image. 
thophoto was used to digitize the boundary around individual impervious features and then calculate the total impervious surface area within each polygon (Figure 3).
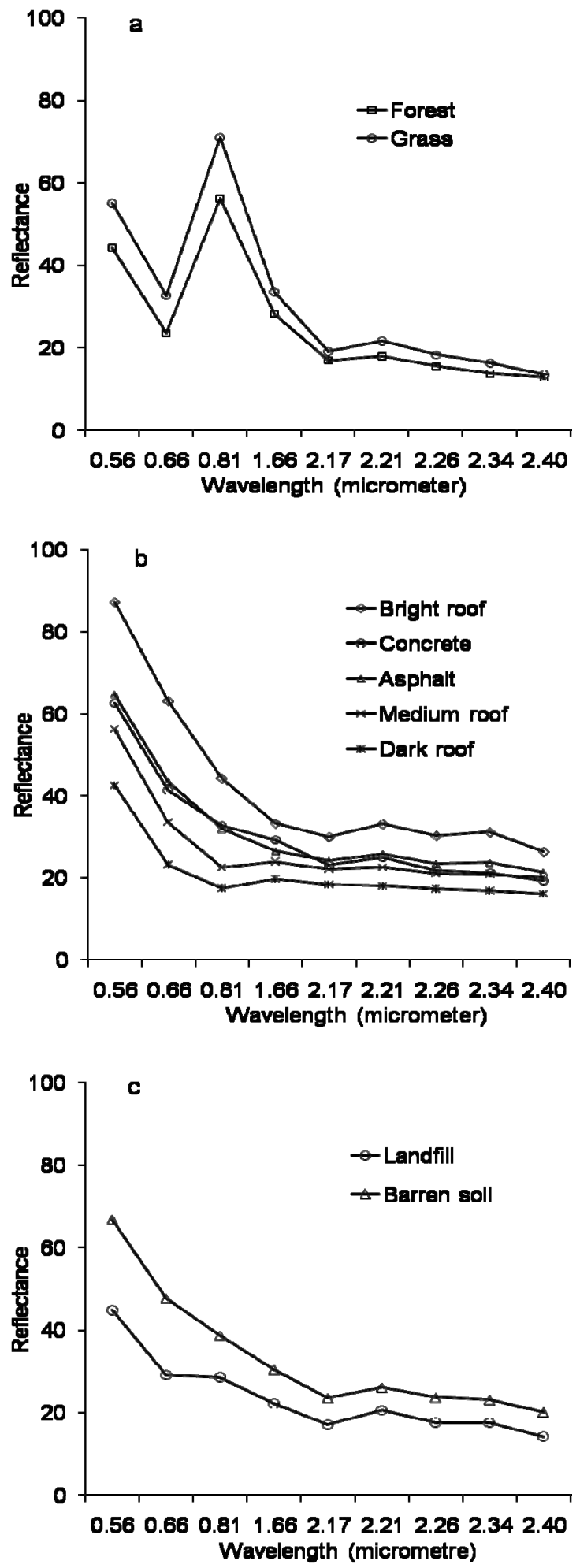

Figure 4. Spectra of endmembers selected from the ASTER image based on the land use/cover map and field observation.

\section{Results}

Figure 4 illustrates the reflectance spectra of endmembers derived from the ASTER image. The spectra of forest and grass show typical spectral reflectance characteristics of healthy green vegetation, i.e., chlorophyll absorption in red region and high scattering in near-infrared region (Figure 4a), which makes them very easy to separate from other surfaces. In the five impervious surfaces in Figure 4b, the bright building roof has the highest reflectance while the dark roof has the lowest reflectance. The surfaces of concrete and asphalt have very similar reflectance spectra, which are also similar with the reflectance of landfills and barren soil (Figure 4c). This makes the separation among them very difficult. Figure 5 is a scatter plot between the actual impervious surface calculated from orthophoto and the estimated imperviousness from ASTER data using the SMA and NDVI approaches. The estimated impervious surface explained 80 to 90 percent of the variation in actual impervious surface by a linear regression model. The reason for the small R-square value of the SMA approach is because the SMA is based on the spectral unmixing of similar proportions of vegetation, impervious surfaces and soil in an area, but the proportion of barren soil in this urban watershed is very small. In this situation, the NDVI approach can be used to get a better result.

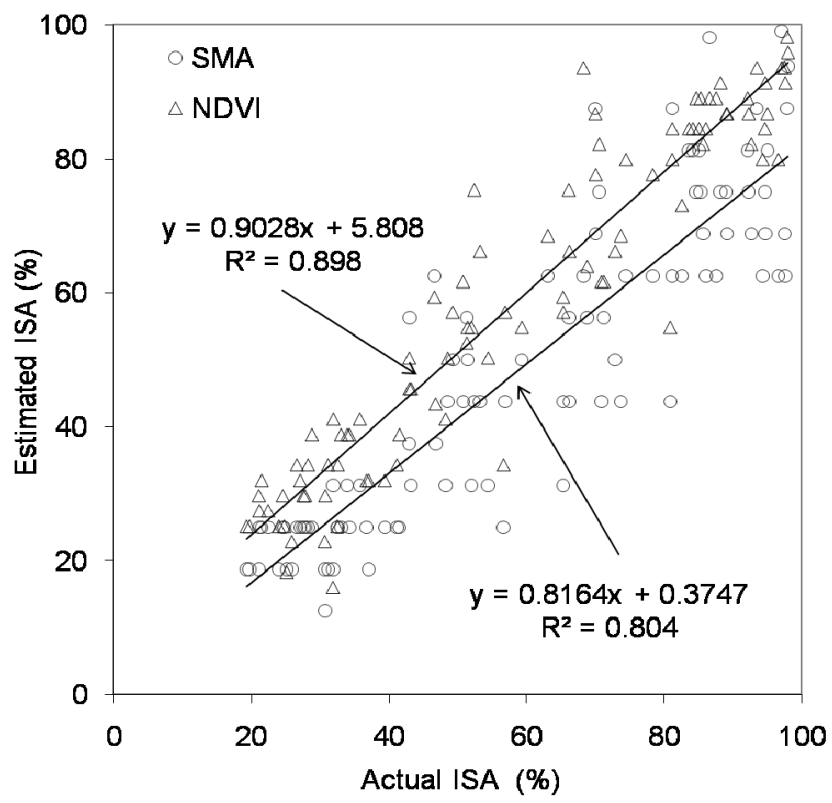

Figure 5. Scatter plot between the actual imperviousness calculated from an orthophoto and the impervious surface areas estimated from ASTER image using the SMA and NDVI approaches.

Figure 6 shows the land use/cover in 2002, calculated NDVI and the estimated impervious surfaces using the SMA and NDVI for a $70 \mathrm{~km}^{2}$ subset. The subset, located in the middle of WMA-5, is a transition between the rural area in the northern part and the urban area in the southern part of the watershed. Figure 6a shows that this area has diverse land use/co- 


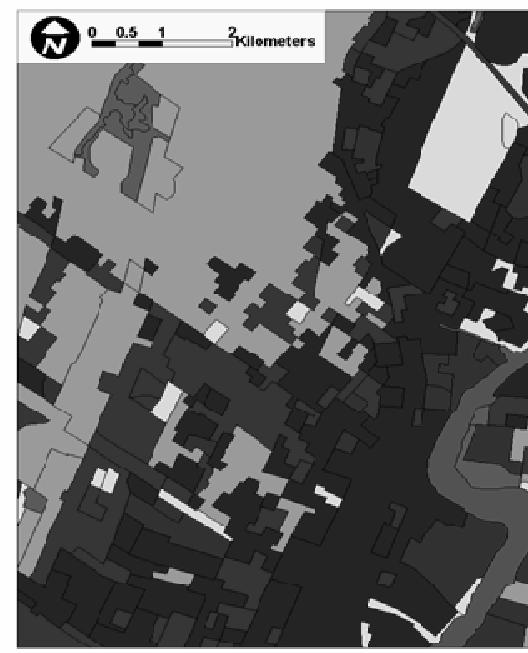

(a)

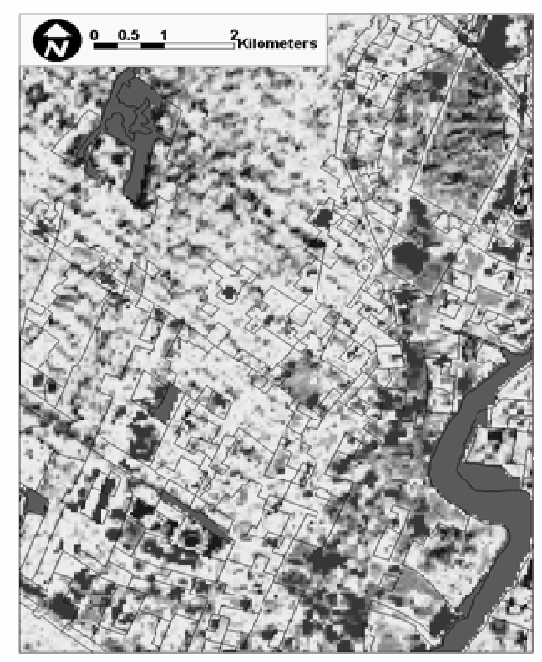

(c)

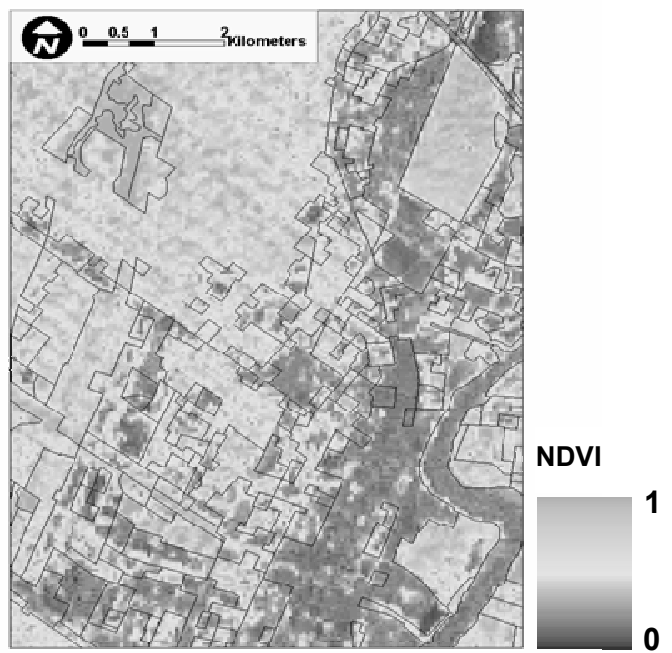

(b)

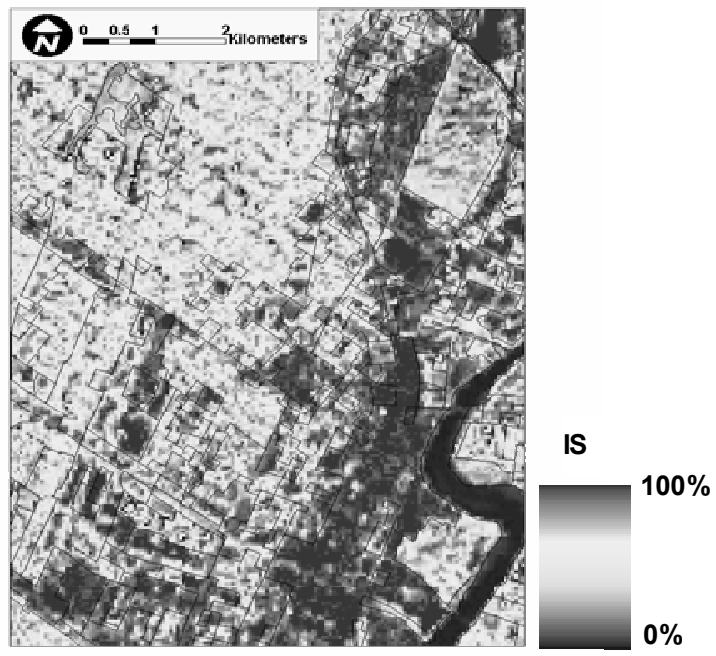

(d)

Figure 6. (a) Land use/cover map of the subset, (b) calculated NDVI from the ASTER image of the subset, (c) impervious surfaces estimated using the SMA approach, and (d) impervious surfaces estimated using the NDVI approach.

vers, from low-density residential and vegetation in the upper left corner, to high-density residential, industrial and water in the lower right corner. The high NDVI value in an area in the upper right corner, labeled as "other urban" in the land use/cover map, indicates that this is a city park (Figure 6b). Impervious surfaces derived from the SMA approach in Figure $6 \mathrm{c}$ show a much clearer pattern in surface imperviousness: pixels with high imperviousness distributed in high-density residential and industrial areas while pixels with low imperviousness in low-density residential and vegetated areas. The impervious surfaces derived from the NDVI approach is presented in Figure 6d, which matches pretty well with the existing land use/cover map. The impervious gradients range from low imperviousness in water, vegetated and low-density residential areas to high imperviousness in high-density residential and industrial areas. This result is also consistent with the results obtained using high-resolution color-infrared orthophoto as described above.

\section{Discussions and Conclusions}

This study demonstrates the utility of using ASTER data to estimate impervious surface areas in an urban watershed using different approaches. While the SMA is useful for mapping impervious surfaces in urban environments with equally distributed components of vegetation, impervious surfaces and soil, the NDVI approach is recommended for estimating impervious surfaces in urban watersheds with small proportion 
of barren soil. The methods described here are less labor intensive compared to digitization of aerial photographs, but resulted in the same level of accuracy. Pixel-based approaches are more accurate and better represent the gradation of impervious values across ground features than traditional methods of assigning an assumed impervious value to a land cover type. These methods can be adopted by land use planners, especially city planning managers who need to evaluate storm water runoff, heat island effects and the protection of green corridors in an urban watershed.

Although the methods presented in this study are straightforward and simple so that people can adopt them to get a quick estimation of impervious surfaces for an urban watershed, there is still some space to improve. First, the bright roofs with high albedos have higher reflectance than pavements such as concrete and asphalt, indicating that impervious surfaces can not be a single endmember due to its complexity. By combining the high albedo endmember (e.g. the bright roof) and the low albedo endmember (e.g. the parking lot), one may achieve more accurate impervious surfaces fraction in an urban environment. Second, we did not consider the shades from buildings and tree crowns in the SMA. Although this remains the principal source of error in using high-resolution remotely sensed data, the assumption that all areas under tree crowns are permeable will underestimate the impervious surfaces area. Finally, since no in situ data was available at the time of the ASTER image acquisition, we used the New Jersey statewide orthophoto acquired in 2002 as the reference data in accuracy assessment. Although not much change on land use/ cover is assumed within a one-year period, the subtle changes may still result in errors in the final product. In the future, obtaining in situ ground truth data at the same day the satellite passes over could potentially improve the accuracy of the results.

Acknowledgments. The authors wish to thank all anonymous reviewers for their constructive and valuable comments and suggestions.

\section{References}

Abrams, M. (2000). ASTER: data products for the high spatial resolution imager on NASA's EOS-AM1 platform, Int. J. Remote Sens., 21, 847-861.

Arnold, Jr.C.L. and Gibbons, C.J. (1996). Impervious surfaces coverage: the emergence of a key environmental indicator, Journal of the American Planning Association, 62, 243-258, doi: $10.1080 / 01944369608975688$.

Cablk, M.E. and Minor, T. (2003). Detecting and discriminating impervious cover with high-resolution IKONOS data using principal component analysis and morphological operators, Int. J. Remote Sens., 24, 4627-4645, doi:10.1080/0143116031000102539.

Carlson, T.N. and Ripley, D.A. (1997). On the relation between NDVI, fractional vegetation cover, and leaf area index, Remote Sens. Environ., 62, 241-252, doi:10.1016/S0034-4257(97)00104-1.

Civco, D.L., Hurd, J.D., Wilson, E.H., Arnold, C.L. and Prisloe, Jr.M.P. (2002). Quantifying and describing urbanizing landscapes in the northeast United States, Photogramm. Eng. Rem. Sens., 68, 1088-1090.

Dougherty M., Dymond, R.L., Goetz, S.J., Jantz, C.A. and Goulet, N.
(2004). Evaluation of impervious surface estimation in a rapidly urbanizing watershed, Photogramm. Eng. Rem. Sens., 70, 12751284.

Forster, B.C. (1985). An examination of some problems and solutions in monitoring urban areas from satellite platforms, Int. J. Remote Sens, 6, 139-151.

Gilabert, M.A., Garcia-Haro, F.J., and Melia, J. (2000). A mixing modeling approach to estimate vegetation parameters for heterogeneous canopies in remote sensing, Remote Sens. Environ, 72, 328345, doi:10.1016/S0034-4257(99)00109-1.

Gillies, R.R., Carlson, T.N., Cui, J., Kustas, W.P. and Humes, K.S. (1997). A verification of the 'triangle' method for obtaining surface soil water content and energy fluxes from remote measurements of the Normalized Difference Vegetation Index (NDVI) and surface radiant temperature, Int. J. Remote Sens., 18, 3145-3166.

Harrison, J., Hayward, P., and Walker, B. (2001). Lullwater Fork Improvement Project (Atlanta, GA USA): Integrating Innovative Urban Watershed, Hydrology and Planning Approaches with "the Usual" Monitoring, Proceedings of the 6th National Volunteer Monitoring Conference: Moving Into the Mainstream, April 26-29, 2000. Austin, TX. U.S. Environmental Protection Agency, EPA 841-R-01-001, pp. 129-134.

Jensen, R.J. (2005). Introductory Digital Image Processing: A remote sensing perspective, New Jersey: Prentice-Hall, Inc.

Ji, M. and Jensen, J.R. (1999). Effectiveness of subpixel analysis in detecting and quantifying urban impervious from Landsat Termatic Mapper imagery, Geocarto Int., 14, 33-42.

$\mathrm{Lu}, \mathrm{D}$. and Weng, Q. (2004). Spectral mixture analysis of the urban landscape in Indianpolis with Landsat ETM+ imagery, Photogramm. Eng. Rem. Sens., 70 (9), 1053-1062.

Mesev, T.V. (1998). The use of census data in urban image classification, Photogramm. Eng. Rem. Sens., 64, 431-438.

Phinn, S., Stanford, M., Scarth, P., Murray, A.T. and Shyy, P.T. (2002). Monitoring the composition of urban environments based on the vegetation-impervious surface-soil (VIS) model by subpixel analysis techniques, Int. J. Remote Sens., 20, 4131-4153.

Ridd, M. (1995). Exploring a V-I-S (vegetation-impervious surfacesoil) model for urban ecosystem analysis through remote sensing: comparative anatomy for cities, Int. J. Remote Sens., 16, 2165 2185 .

Roberts, D.A., Gardner, M., Church, R., Ustin, S., Scheer, G. and Green, R.O. (1998). Mapping chaparral in the Santa Monica moun- tains using multiple endmember spectral mixing models, Remote Sens. Environ., 65, 267-279, doi:10.1016/S0034-4257(98) 00037-6.

RSI (Research Systems Inc.) (2004). ENVI Users Guide (Version 4.1), Boulder, Colorado, USA, pp. 1084.

Sabol, D.E., Gillespie, A.R., Adams, J.B., Smith, M.O. and Tucker, C.J. (2002). Structural stage in pacific northwest forests estimated using simple mixing models of multispectral images, Remote Sens. Environ., 80, 1-16, doi:10.1016/S0034-4257(01)00245-0.

Sawaya, K.E., Olmanson, L.G., Heinert, N.J., Brezonik, P.L. and Bauer, M.E. (2003). Extending satellite remote sensing to local scales: land and water resource monitoring using high resolution imagery, Remote Sens. Environ., 88, 144-156.

Slonecker, E.T., Jennings, D., and Garofalo, D. (2001). Remote sensing of impervious surfaces: A review, Remote Sens. Rev., 20, 227255.

Small C. (2001). Estimation of urban vegetation abundance by spectral mixture analysis, Int. J. Remote Sens., 22, 1305-1334.

van der Meer, F. and de Jong, S.M. (2000). Improving the results of spectral unmixing of Landsat Thematic Mapper imagery by enhancing the orthogonality of end-members, Int. J. Remote Sens., 21, 2781-2797. 
Wang, Y. and Zhang, X. (2004). A SPLIT model for extraction of subpixel impervious surface information, Photogramm. Eng. Rem. Sens., 70, 821-828.

Ward, D., Phinn, S.R. and Murray, A.T. (2000). Monitoring growth in rapidly urbanizing areas using remotely sensed data, Prof. Geogr. 52, 371-386, doi:10.1111/0033-0124.00232.

Wu, C. and Murray, A.T. (2003). Estimating impervious surface distribution by spectral mixture analysis, Remote Sens. Environ., 84, 493-505, doi:10.1016/S0034-4257(02)00136-0.

$\mathrm{Wu}, \mathrm{C}$. (2004). Normalized spectral mixture analysis for monitoring urban composition using ETM+ imagery, Remote Sens. Environ., 93, 480-492, doi:10.1016/j.rse.2004.08.003.

Xian, G. and Crane, M. (2005). Assessments of urban growth in the Tampa Bay watershed using remote sensing data, Remote Sens. Environ., 97, 203-215, doi:10.1016/j.rse.2005.04.017.
Yang, L., Huang, C., Homer, C.G., Wylie, B.K. and Coan, M.J. (2003). An approach for mapping large-area impervious surfaces: synergistic use of Landsat-7 ETM+ and high spatial resolution imagery, Can. J. Remote Sens., 29, 230-240.

Yuan, F. and Bauer, M.E. (2007). Comparison of impervious area and normalized difference vegetation index as indicators of surface urban heat island effects in Landsat imagery, Remote Sens. Environ., 106, 375-386, doi:10.1016/j.rse.2006.09.003.

Zhang, L., Li, D., Tong, Q. and Zheng, L. (1998). Study of the spectral mixing model of soil and vegetation in PoYang lake area, China, Int. J. Remote Sens., 19, 2077-2084.

Zhu, G. and Blumbergerg, D.G. (2002). Classification using ASTER data and SVM algorithms, the case study of Beer Sheva, Israel, Remote Sens. Environ., 80, 233-240, doi:10.1016/S0034-4257(01) 00305-4. 